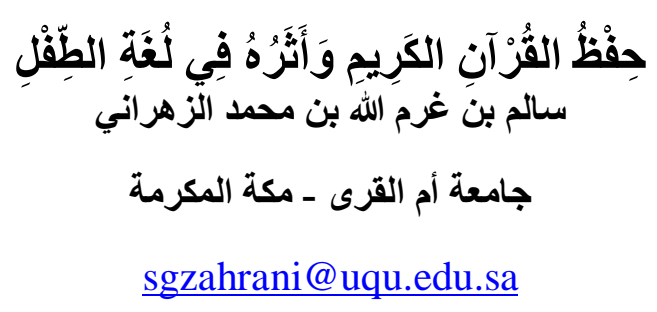

DOI: https://doi.org/10.36231/coedw/vol30no4.1

Received 29/10/2019

Accepted 1/12/2019

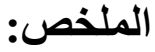

في هذا العصر - الذي داهمت في الأخطار لغة الفصاحة والبيان - يبقى القرآن الكريم أعظم حافظ للغة السليمة ، وأكبر معين

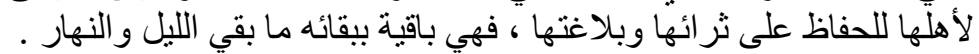

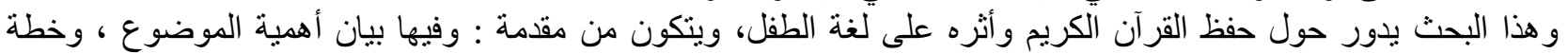

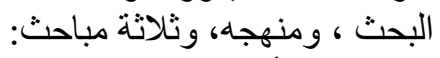

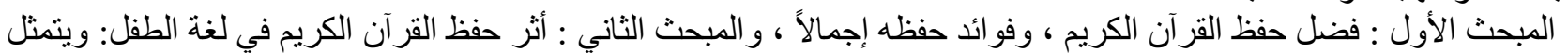

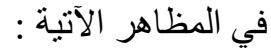
ـ ـ تذوق الكلام الجميل، - سلامة النطق وفصاحة اللسان، ـ سلامة الإعراب، ـ الثراء اللفظي وبلاغة التعبير، - إتقان القراءة

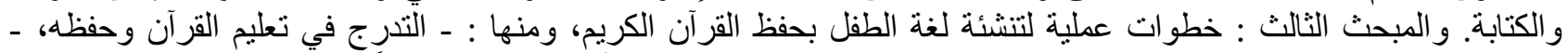

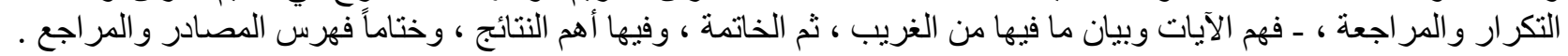

كلمات مفتاحية : أثر ، حفظ القرآن ، لغة الطفل .

\section{Memorizing the Holy Quran and its Impact on Child's Language}

\author{
Salem bin Ghormallah Alzahrani \\ Umm Al Qura University / Makkah, KSA
}

\begin{abstract}
In this age - in which dangers have raided language eloquence and statement - the Quran remains the greatest preservence of the sound language, and the greatest supporter for its people to preserve its richness and eloquence. It remains with it, as the night and day remain. This study revolves around the preservation of the Holy Quran and its impact on the language of the child. It consists of an introduction which includes the importance of the subject, the research plan, and methodology, and three sections. The first one is about the virtue of memorizing the Quran, and the benefits of memorizing it in general, and the second section deals with the impact of memorizing the Quran in the language of the child. It is represented in the following manifestations: - Tasting beautiful speech, - The integrity of pronunciation and eloquence of the tongue, - The integrity of the expression, - Verbal richness and eloquence of expression, - Proficiency in reading and writing. The third section is about the practical steps to nurture the language of the child by memorizing the Holy Quran, including: - Graduation in the teaching and memorization of the Quran, - Repetition and revision, - Understanding the verses and the statement of what is strange, -Then the conclusion, and the most important results, and finally the index of sources and references.
\end{abstract}

Keywords: Effect, memorizing the Quran, the language of the child 


\section{المقدمة}

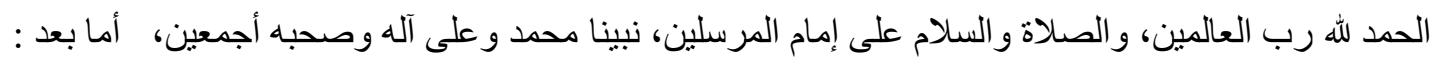

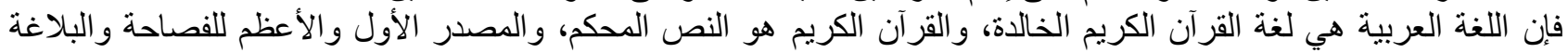

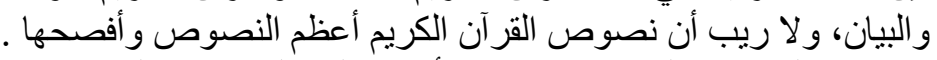

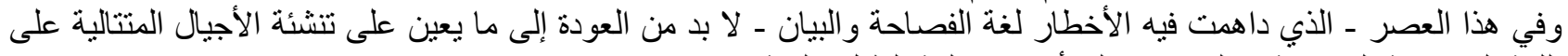

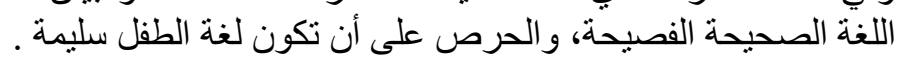
ويقى القرآن الكريم أعظم حافظ للغة السليمة، وأكبر معين لأهلها للحفاظ على ثرائها وبلاغتها، فهي باقية ببقائه ما بقي الليل و النهار .

و هذا البحث يتناول حفظ القرآن الكريم وأثره في لغة الطفل، وسيكون وفق الخطة الآتية :

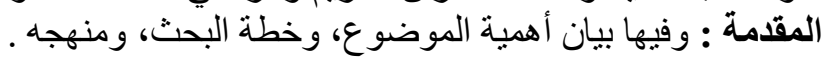

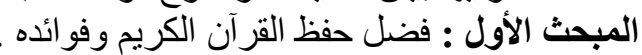

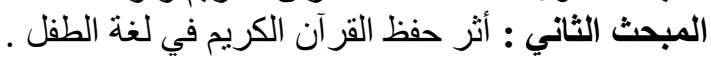

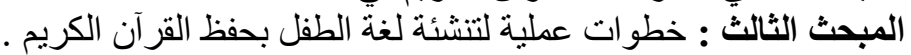

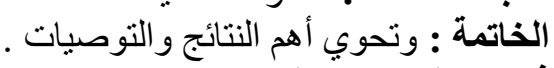
فهرس المصادر والمراجع. والهم

$$
\text { منهج البحث في هذا البحث المنهج الاستقر ائي الوصفي التحليلي، واتبعت في ذلك الخطوات الآتية : }
$$

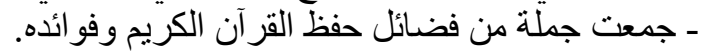

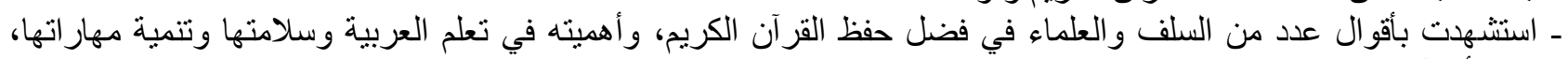

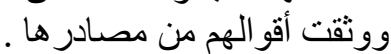

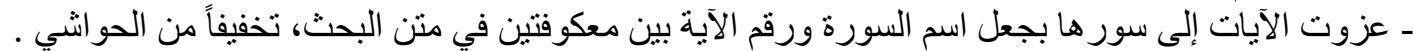

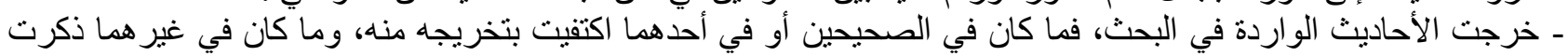
حكم العلماء عليه . ـ أفدت من نتائج عدد من الدراسات عن تأثر الأطفال بحفظ القرآن الكريم . هذا وأسأل الله تعالى التوفيق والسداد، وصلى الله وسلم على نبينا محمد و على آله وصحبه أجمعين . 


\section{المبحث الأول : فضل حفظ القرآن الكريم وفوائده :}

إن حفظ القر آن الكريم من أفضل الأعمال، ومنزلة حافظه عظيمة، وقد جاءت نصوص عديدة تبين منزلته، وما هو موعود به و ومن ذللك : قول النبي صلى الله عليه وسلم : 》ا إن لله أهلين من الناس، قالوا : من هم يارسول الله ؟ قال : أهل القرآن هم أهل الله وخاصته « (1) .

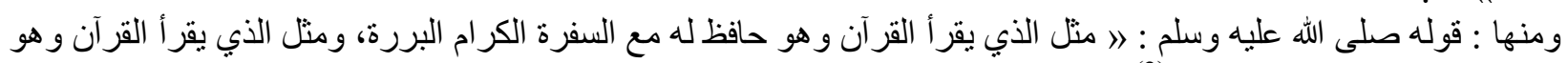

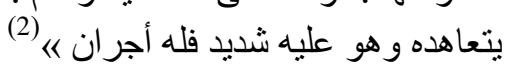

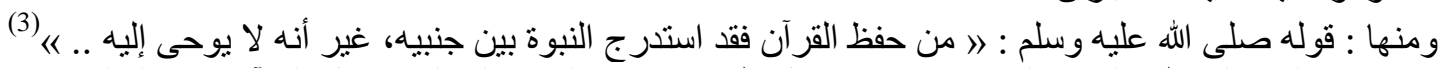

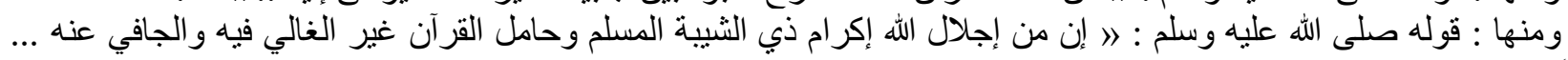

ومنها : تقديمه صلى الله عليه وسلم حافظ القرآن و الأكثر حفظاً على غيره في مو اضع مختلفة:

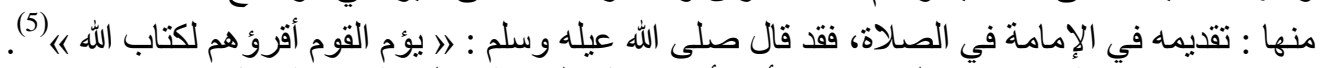

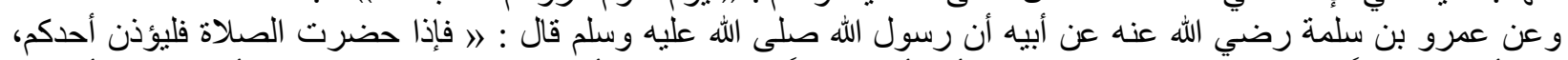

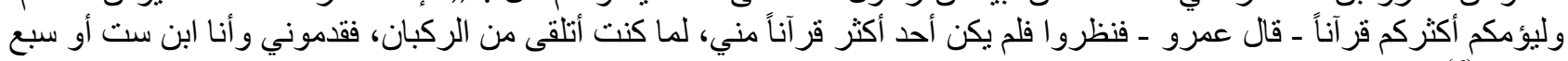

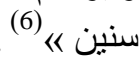

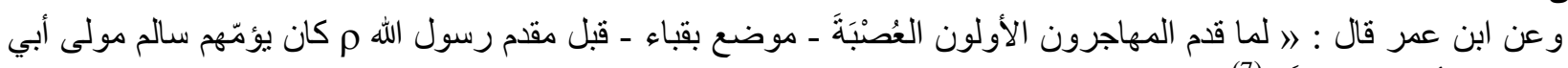

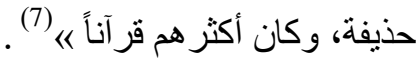

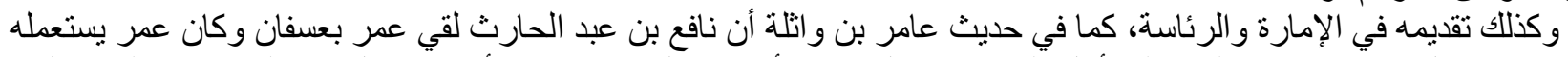

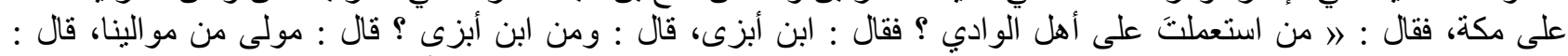

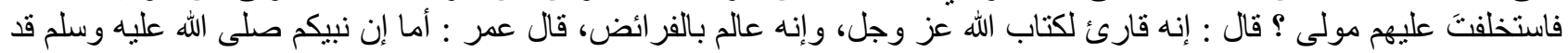

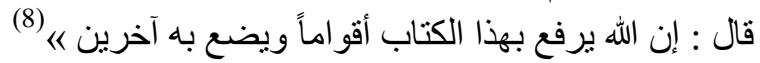

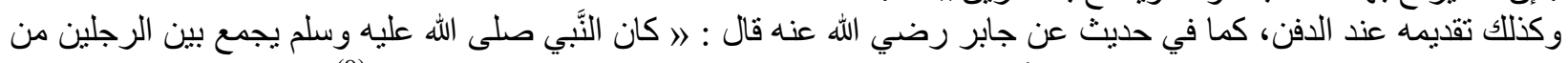

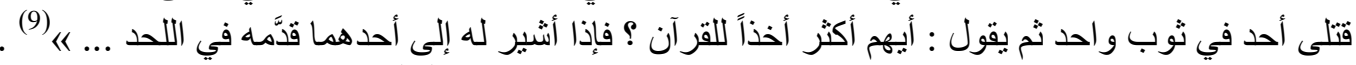

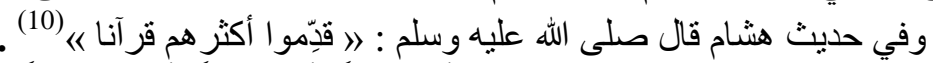

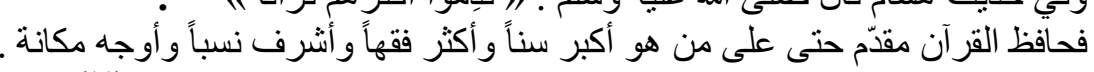

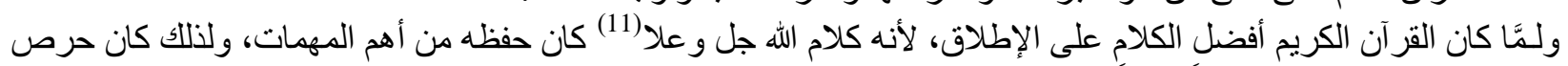

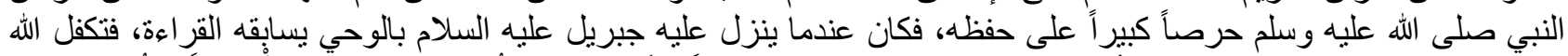

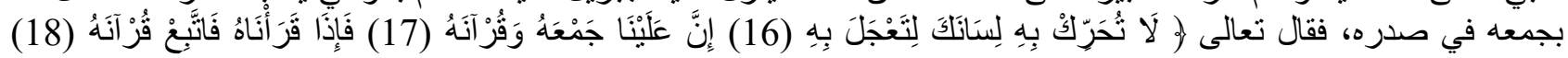

وحرص السلف على حفظه، ورغَّبو ا فيه، وكانو ا يشيدون بمن يحفظ العلم عموماً، كما قال الرحبي في منظومته(12) : [كروة القيامة]

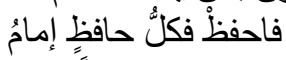

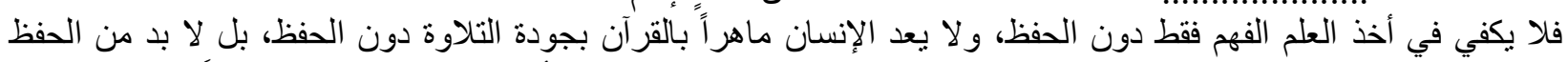

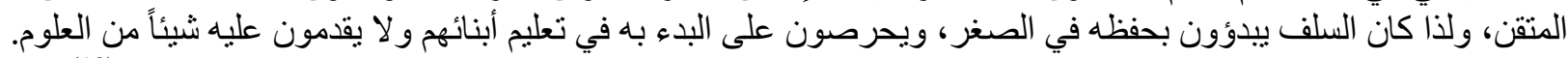

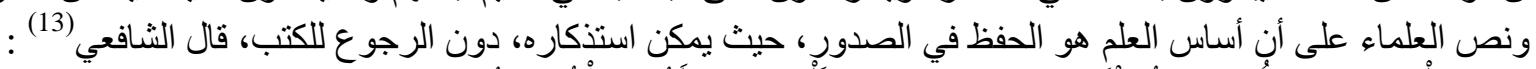

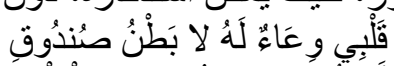

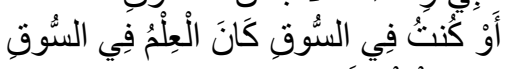

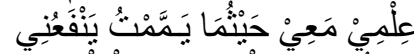

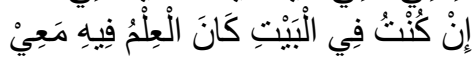

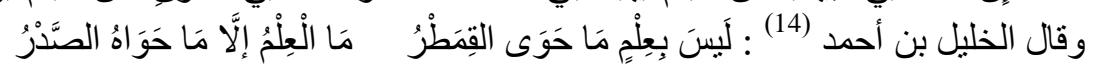
وقال ابن حزم (15) : وقال الخيل

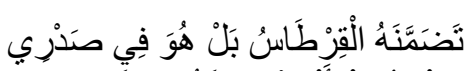

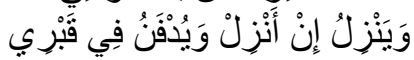

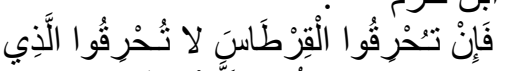

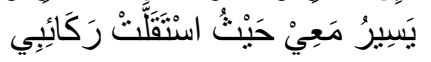

ومن فضائل حفظ القرآن الكريم وفوائده : أن حفظ القرآن وتعلمه خير من متاع الدنيا، فحين يفرح الناس بالارهم والدئ والدينار

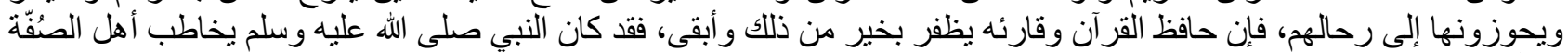

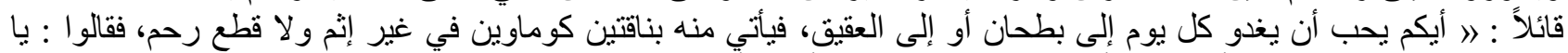

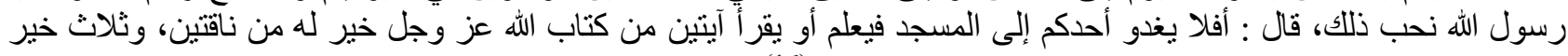

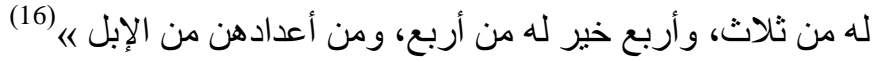




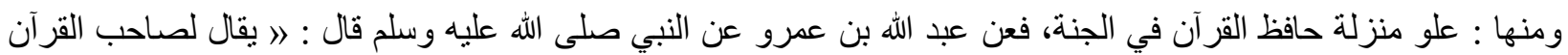

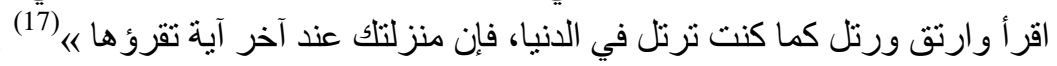

فال ابن حجر الهيثمي : 》ا الخبر خاص بمن يحفظه عن ظهر قلب، لا بمن يقرأ بالمصحف، لأن مجرد القراءة في الخط لا يختلف الناس فيها « (18)

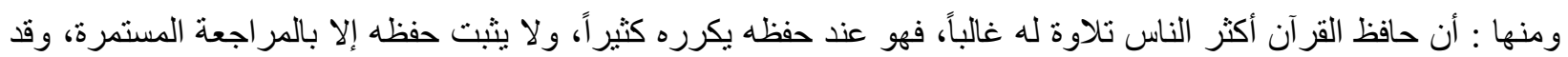

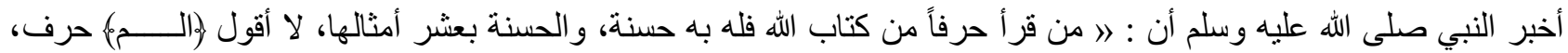
ولكن ألف حرف، و لام حرف، وميم حرف « (19) .

و ونها : أن حافظ القرآن الكريم يستطيع التلاوة في جميع أحواله، يقرأ مانشياً أو مضطجعاً، أو في عمل، يقرأ في السفر أو الحضر، أما غير الحافظ فلا يمكنه ذلك .

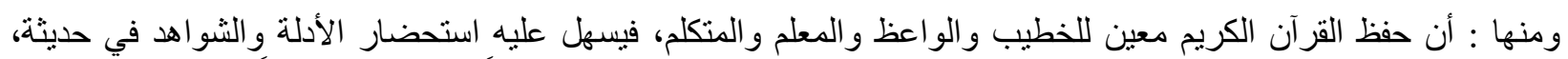

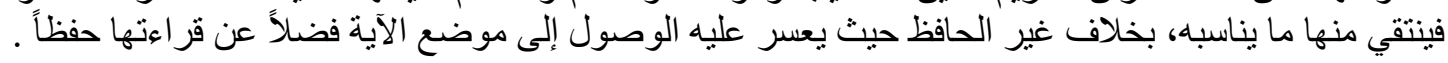

ومنها : أن حفظ القرآن الكريم ينمي مدارك الأطفال ويزيد استيعابهم بدرجة أكبر من غير هم، وله دور كبير في زيادة التحصيل

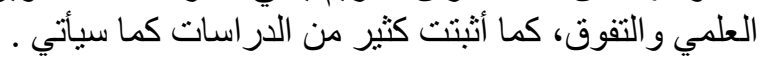

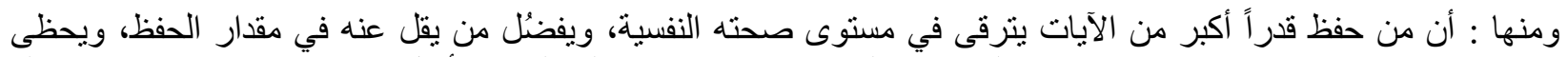

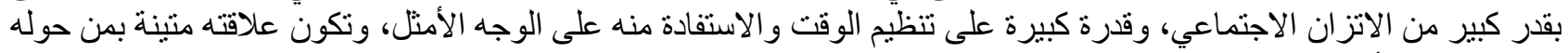
ويحسن اختيار أصدقائه . الاجن.

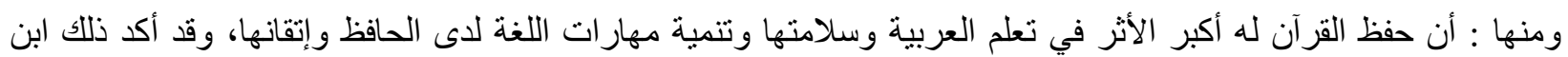

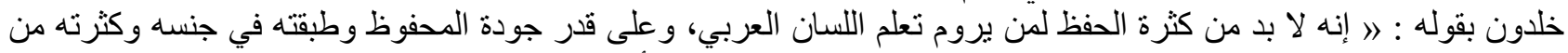

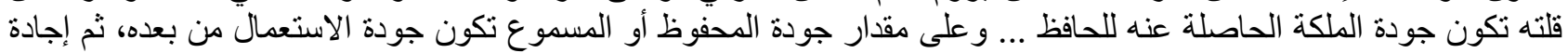

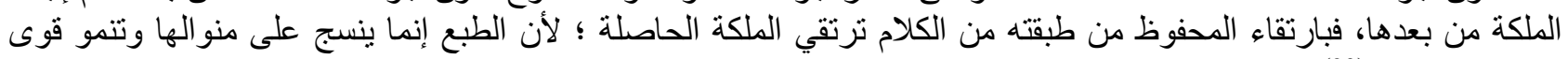

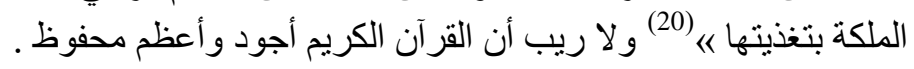


لما كان القرآن الكريم كلام رب العالمين، وفضله على سائر الكلام كفضله تعالى على خلقه، كما ثبت عن رسول الله صلى الله عليه وسلم (21) .

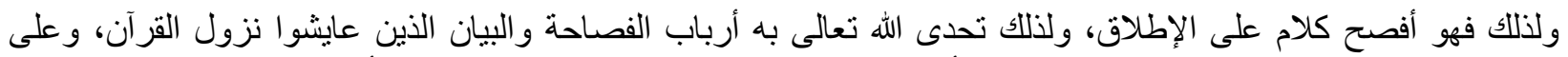

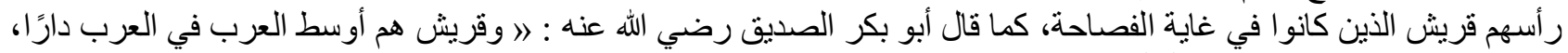

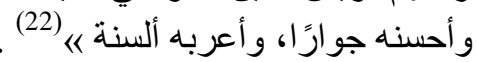

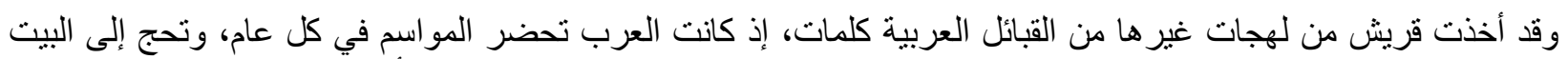

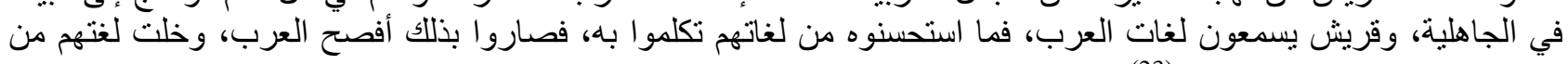
مستبشع اللغات، ومستقبح الألفاظ(23) في لمان

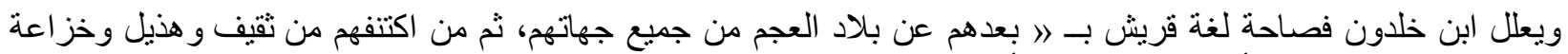

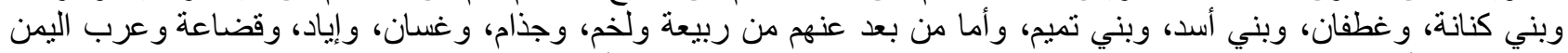

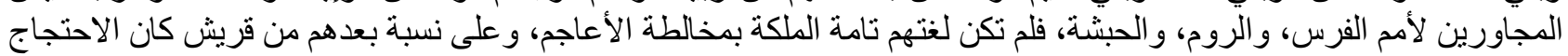

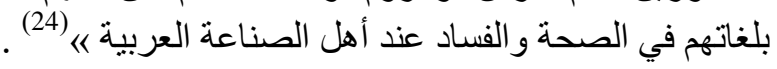

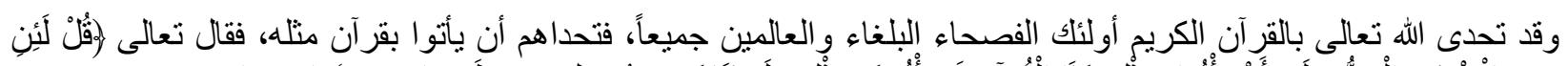

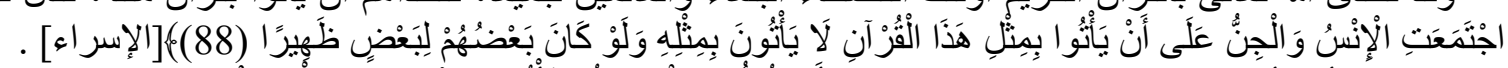

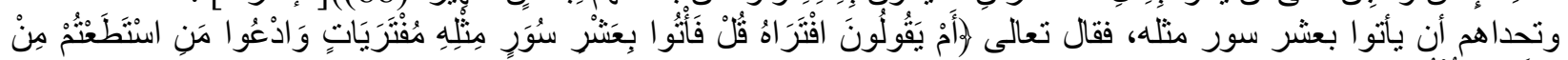

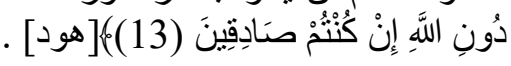

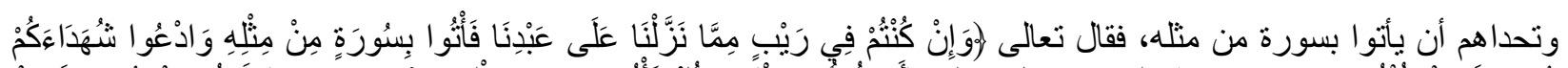

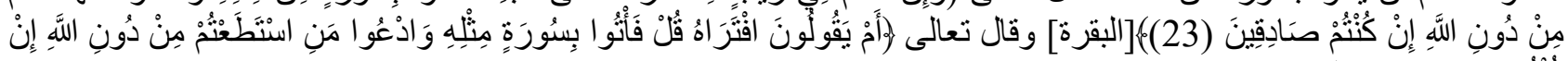

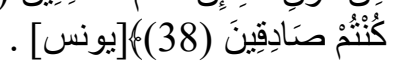

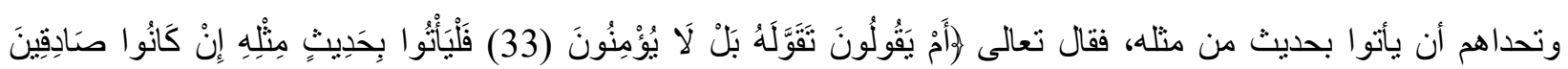

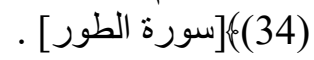

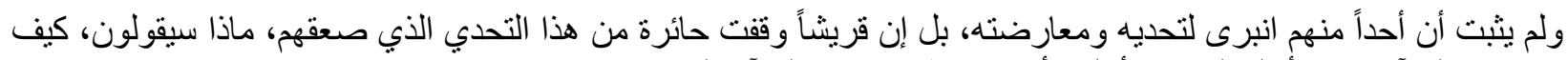

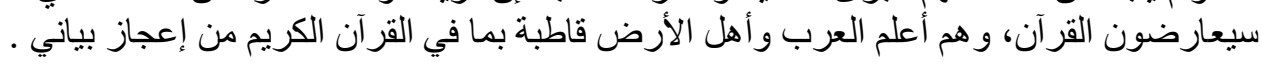

فلم يخامروا بتأليف آيات تعارض آيات القرآن الكريم، لأنهم بذلك سيُّقطون كل هيبة بقيت لهم عند العرب، وسيكونون

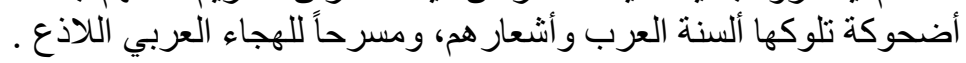

لقد تعجَّبَ المشركون من فصاحة القر آن الكريم التي لم يعهدو ها، ولم يمكنهم أبداً معارضتنها، وما كان منهم إلا أن تعاهدوا فيما

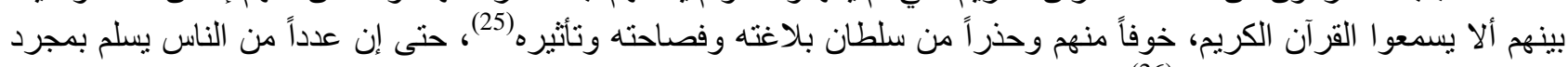

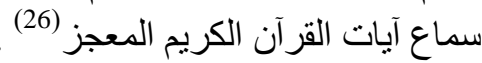

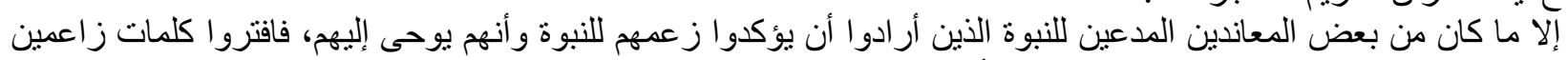

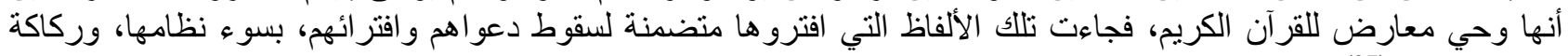
ألفاظها وحبكها (27)

ومن أسرع من يتأثر بفصاحة القرآن ويستقيم به لسانه، ويصح به نطقه، هو الطفل، لكونه صافي القريحة، يتأثر بما يسبق إلى سمعه وفهمه و عقله وقلبه .

قال ابن خلدون : 》 .. تعليم الصغر أثندُ رسوخاً وهو أصل لما بعده ؛ لأن السابق الأول للقلوب كالأساس للملكات و على حسب ئب الأساس وأساليبه يكون حال ما ينبني عليه « (28) 
ويظهر أثر حفظ القرآن الكريم في لغة الطفل في مظاهر عديدة، وهي :

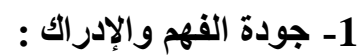

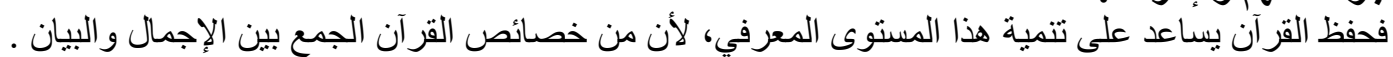

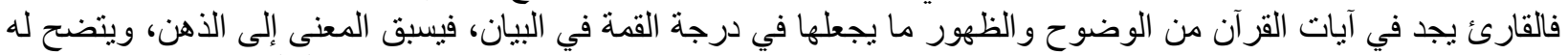

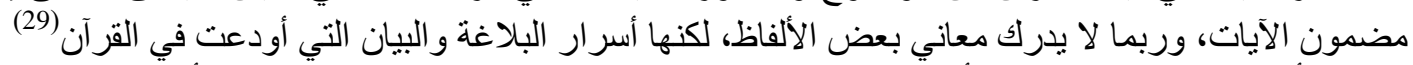

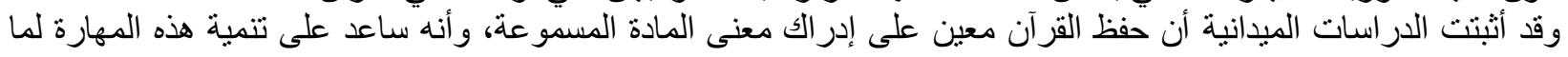

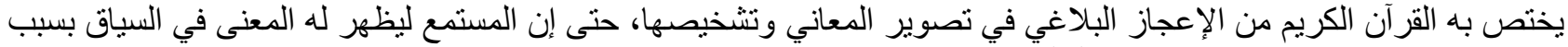

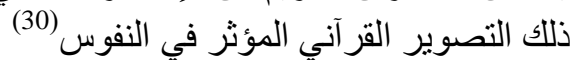
2- 20 - مهارة تذوق الكلام الجميل :

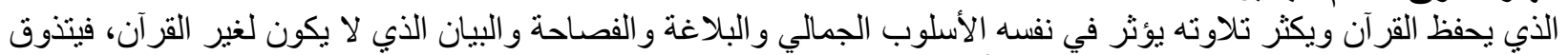

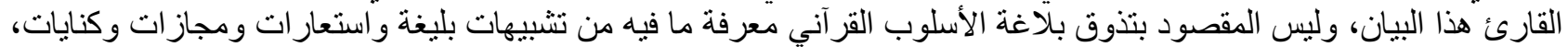

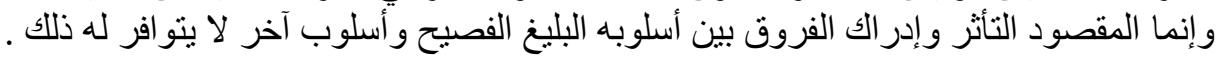

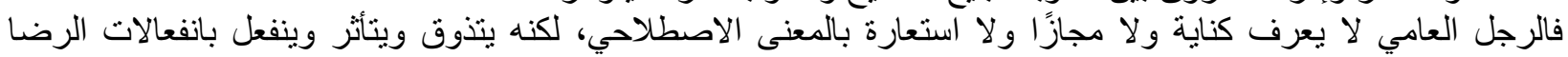

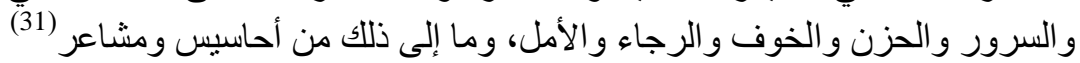

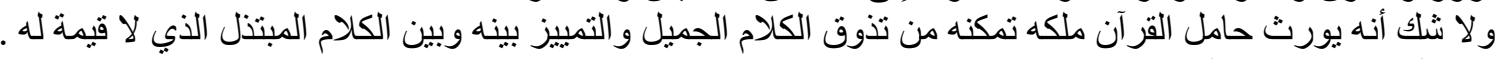

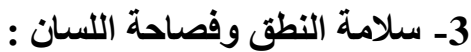

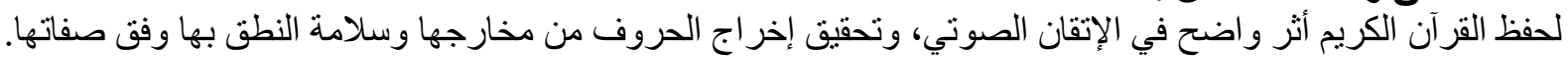

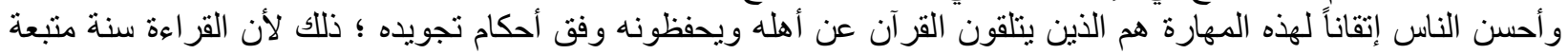

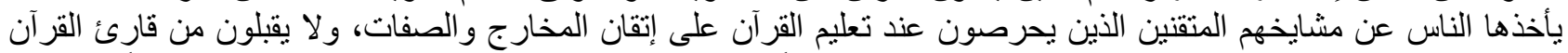

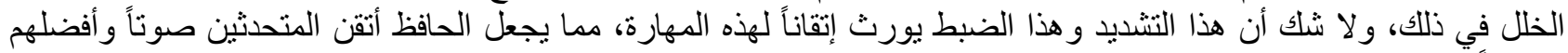

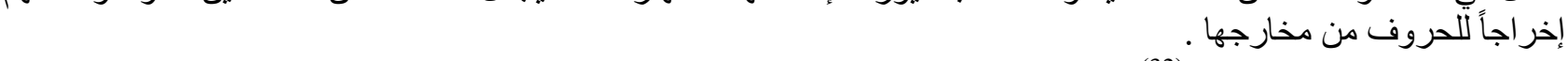
وقد كثفت بعض الدراسات(32) عن نأثر ألسنة هؤلاء الأطفال قبل البدء في تعلمهم التلاوة ومراحل نطقهم بعد مرور أربعة

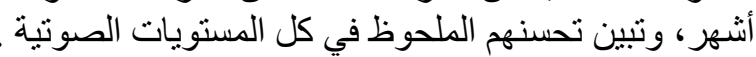

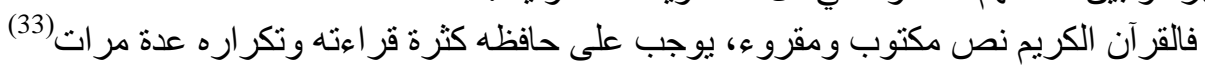

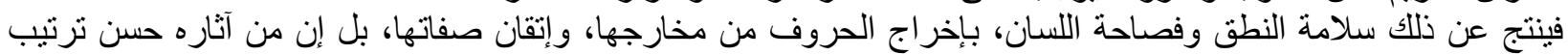

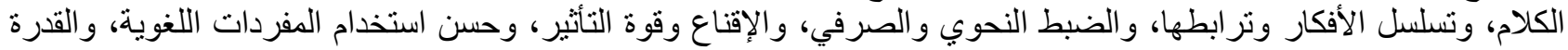

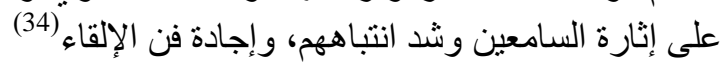

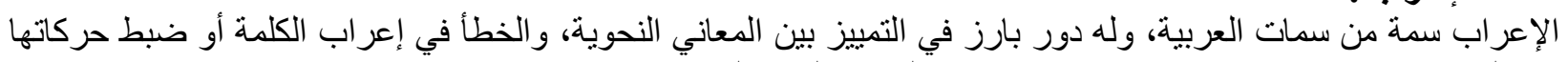

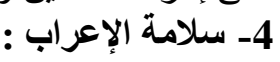

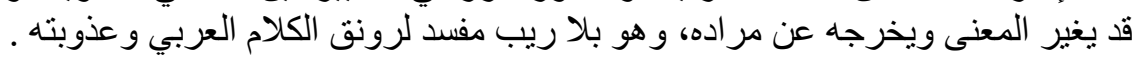

و لا يخفى أن الطفل في صغره يكون خالي الذهن من المكتسبات العلمية و المعرفية، وتزداد معرفته مع الأليام شيبئاً فثيئاً، و أكبر

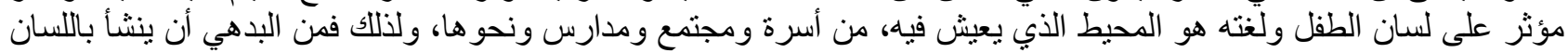

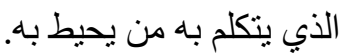

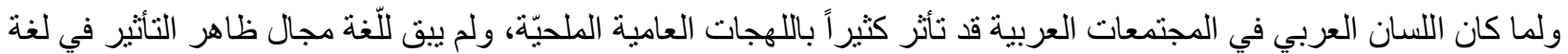

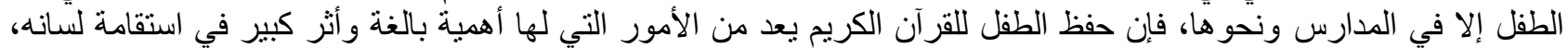

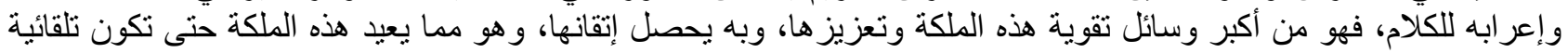

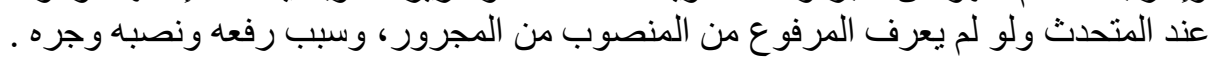

و إن إتقان حفاظ القرآن لهذه المهارة أمر ظاهر و الثواهد و التجارب تثبته، يقول أحد الباحثين : إ وخير شاهد على أن أن من يتقن

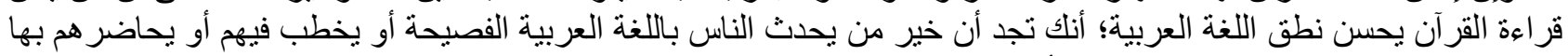
هو ممن لهم اتصال بالقر آن الكريم عامة، أو يجيدون تلاوته خاصة التهة، فإذا استمعت إلى خطيب و لاحظت جودة نطقه للكلمات فاعلم

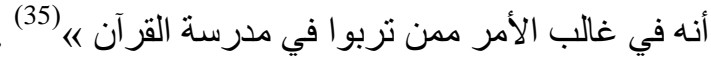

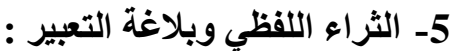

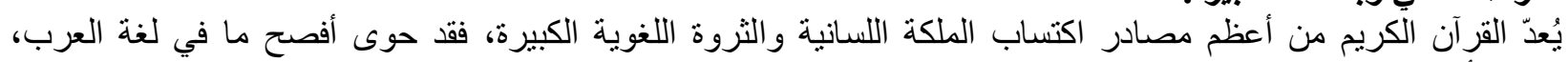


و ألفاظ القرآن الكريم التي يحصلها المرء بحفظه لها، ليست كسائر الألفاظ، بل هي ألفاظ قد بلغت الغاية في الحسن و الفصاحة و والبلاغة .

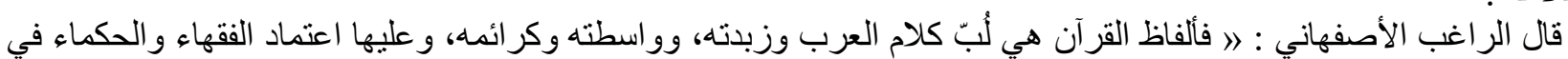

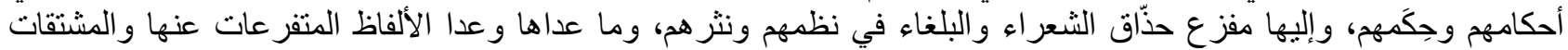

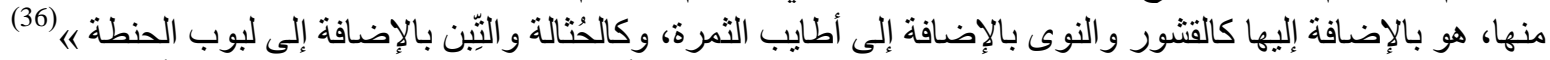

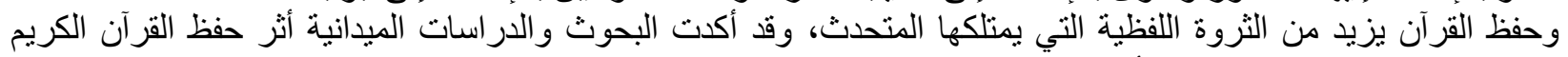

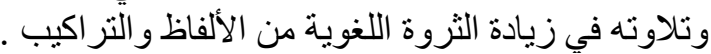

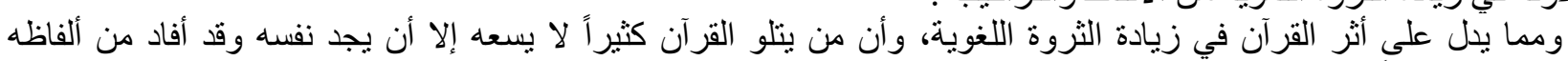

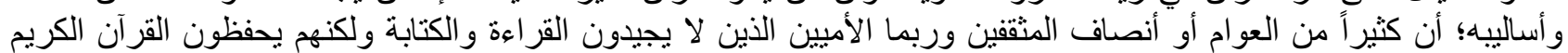

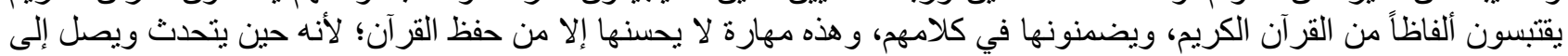

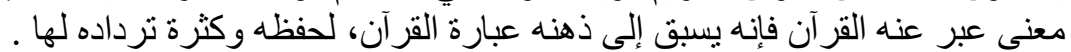

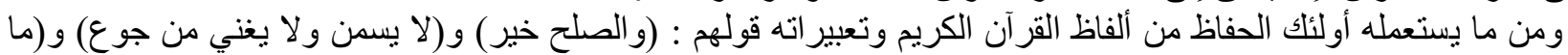

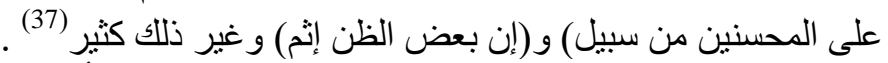

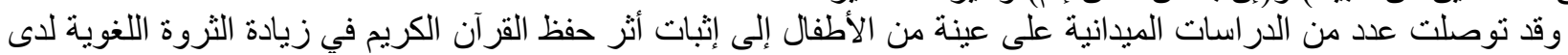

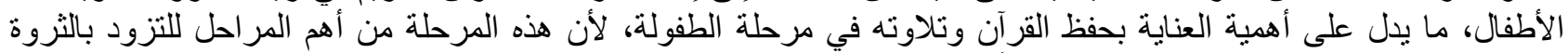

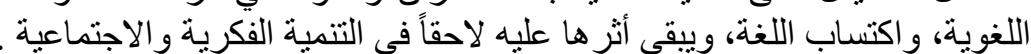

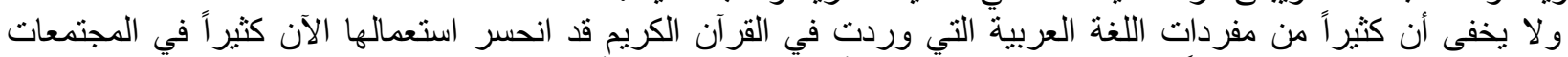

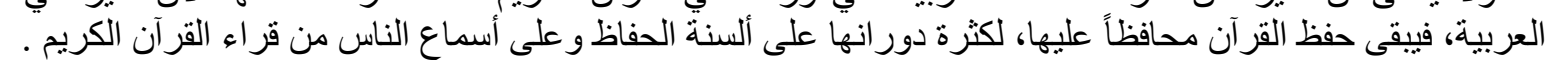
6- 6- إتقان القراعة والكتابة :

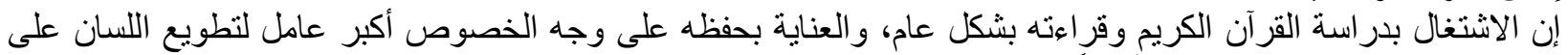

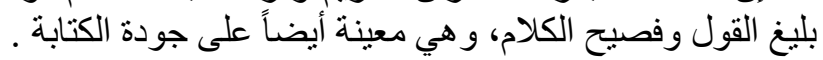

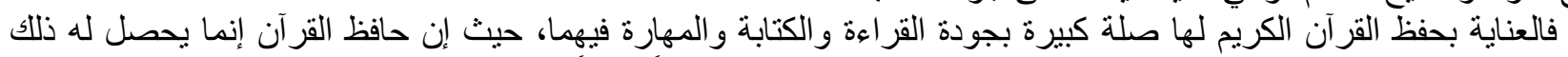

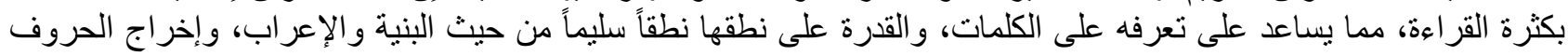

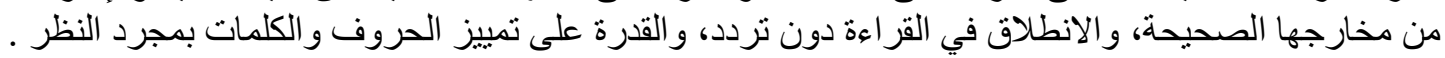

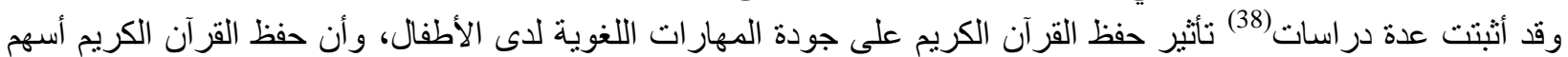

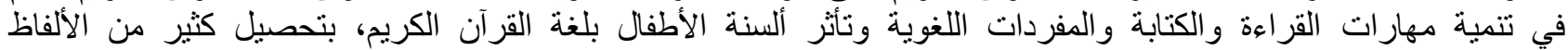

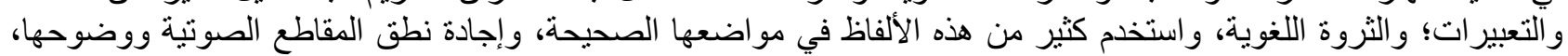

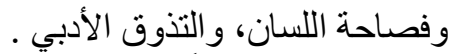
كما أثثتت أيضاً ارتفاع نسبة الإتقان لاى طلاب مدارس تحفيظ القرآن الكريم، وتفوّقهم بشكل كبير على طلاب الددارس الأخرى . وبذللك تتبين العلاقة الإيجابية القوية بين حفظ الأطفال للقر آن الكريم و إتقانهم للغة العربية، وتقدم مستو اهم في مهار اتها المتعددة. 


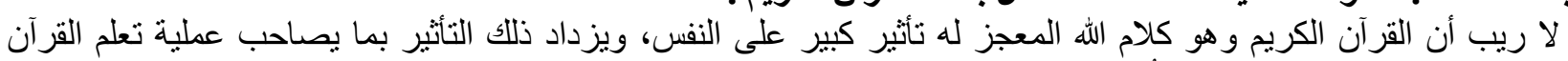

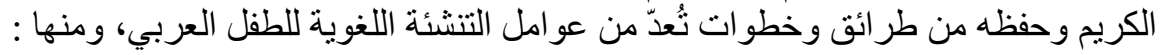

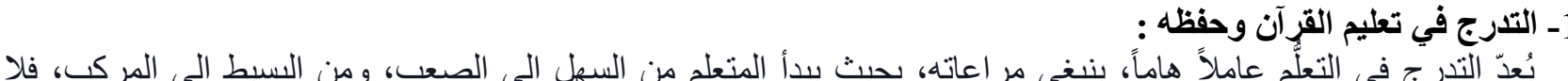

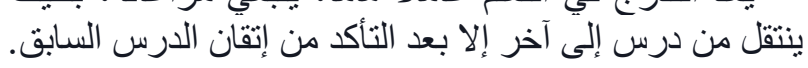

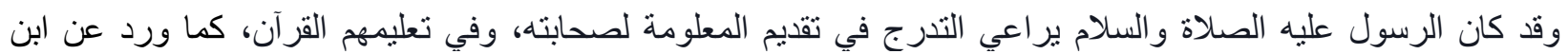

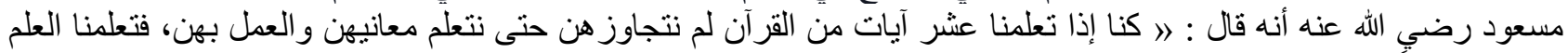

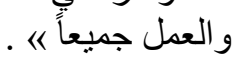

وورد نحوه عن أبي عبد الرحمن السلمي، قال : \ا حدثنا من كان يقرئنا من أصحاب رسول الله صلى الله عليه وسلم أنهم كانوا

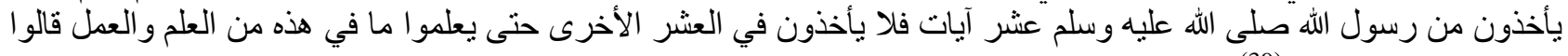

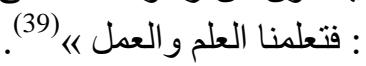

فالتدرج في التعليم يساعد المتعلم على الفهم والتذكر والتطبيق، ويرفع من همة المتعلم ونشاطه ويجعله أكثر شوقاً للاستمرار

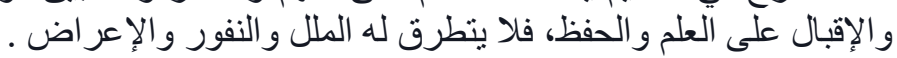

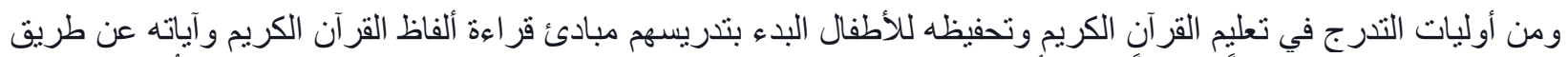

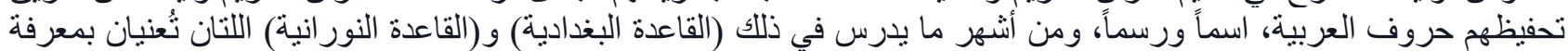

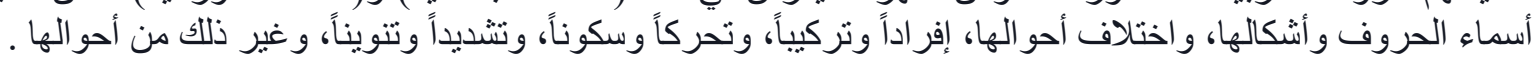

2ـ التكرار و المر اجعة من أعظم أسس تعلم اللغة العربية والعلوم عموماً، ولا سيما في حفظ النصوص، وفي مقدمتها القرآن الكريم،

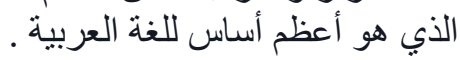

وقد قرر ابن خلدون ذلك وجطله شرطاً لاكتساب الملكة فقال : إ والملكات لا تحصل إلا بتكرار الأفعال؛ لأن الفعل يقع أولاً

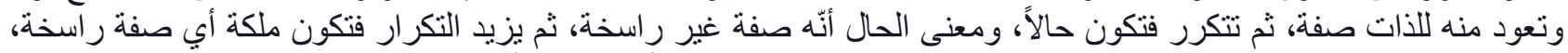

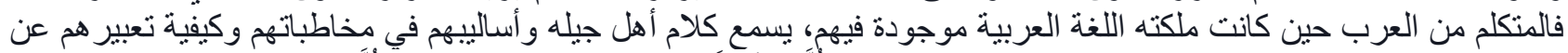

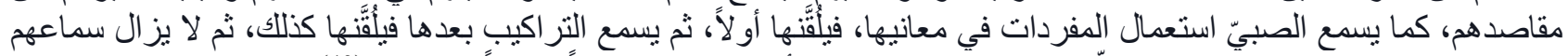

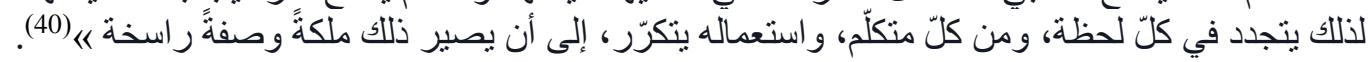
3- فهم الآيات وبيان ما فيها من الغريب :

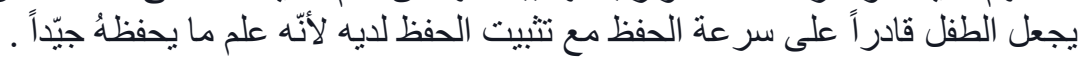

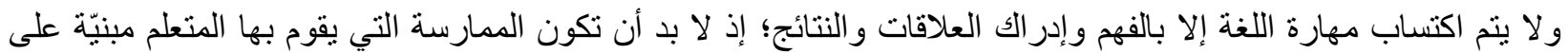

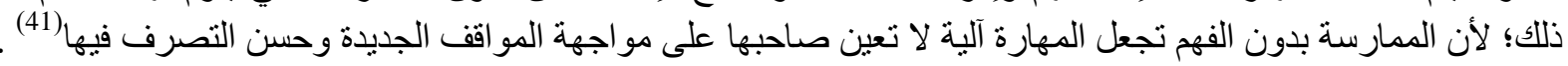

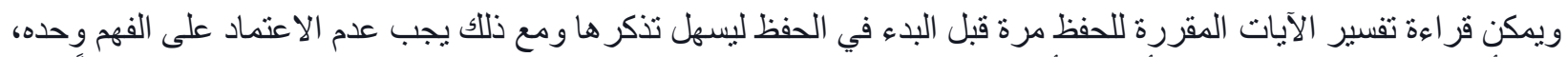

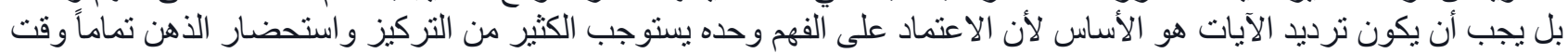
الحفظ.

وكذللك الوقوف مع القصص الو اردة في الآيات وربطها بما ورد منها في أكثر من سورة، فذللك مما يعطي الحافظ تصور آ تاماً

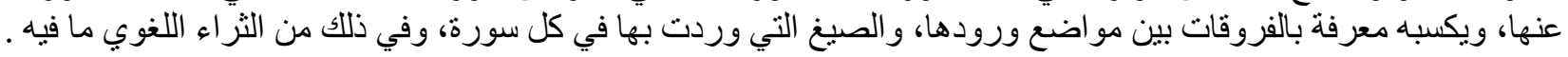
وخاصة عندما تشنمل الآيات على ألفاظ غريية، ليست مما يشيع استعماله في اللغة الحاضرة، و لا يتبين معناها إلا بالرجوع

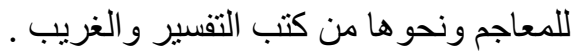

هذه أهم الخطوات العملية لتنشئة لغة الطفل بحفظ القرآن الكريم، و الله تعالى ولي التوفيق، والحمد الله رب العالمين، وصلى الله

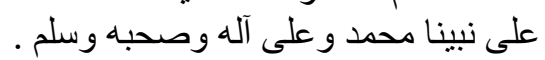




$$
\text { ففي ختام هذا البحث أسجل جملة من أهم النتائج التي ظهرت لي فيه، و هي كما يأني: }
$$

- القر آن الكريم أفضل الكلام على الإطلاق، و هو النص المحكم، و المصدر الأول والأعظم للفصاحة و البلاغة و البيان، و لا ريب أن نصوص القرآن الكريم أعظم النصوص الإطلاق، وهامة للّمان.

ـ - في هذا العصر داهمت الأخطار لغة الفصاحة والبيان ويبقى القرآن الكريم أعظم حافظ للغة السليمة، وأكبر معين لأهلها

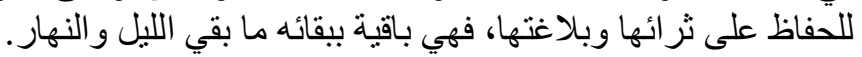

- حفظ القرآن الكريم من أفضل الأعمال، وأهم المهمات، ومنزلة حافظه عظيمة، وقد جاءت نصوص عديدة تبين منزلته، وما

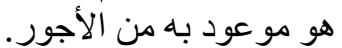

- ل العفي في أخذ العلم الفهم فقط دون الحفظ، ولا يعد الإنسان ماهراً بالقرآن بجودة التلاوة دون الحفظ، بل لا بد من الحفظ

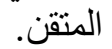

- كان السلف يبدؤون بحفظ القرآن في الصغر، ويحرصون على البدء به في تعليم أبنائهم و لا يقدمون عليه شيئًا من العلوم. - ل لحفظ القرآن الكريم أثر كبير في تعلم العربية وسلامنها وتنمية مهار اتها لدى الحافظ و إتقانها.

- تعليم الصغر أثدُ رسوخاً وهو أصل لما بعده؛ لأن السابق الأول للقلوب كالأساس للملكات و على حسب الأساس وأساليبه يكون حال ما ينبني عليه، كما قرر ابن خلدون.

- يظهر أثر حفظ القرآن الكريم في لغة الطفل في مظاهر عديدة، من أبرزها: جودة الفهم والإدراك، وسلامة النطق وفصاحة

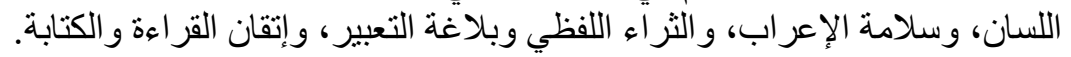

- لتنشئة لغة الطفل بحفظ القرآن الكريم خطوات عملية، من أهمها: التنرج في التعليم، و التكرار و المراجعة، وفهم الآيات وبيان ما فيها من الغريب.

$$
\text { هذا و الله تعالى ولي التوفيق، وصلى الله على نبينا محمد و على آله وصحبه وسلم. }
$$

\section{:Conclusion}

:Praise be to Allaah who is by His grace the good works are done, and after

At the end of this research I record some of the most important results that have appeared to me :in it, namely

The Quran is the best speech ever, the text of the text, and the first and greatest source of eloquence, rhetoric and statement, and there is no doubt that the texts of the Quran the greatest .texts established for the tongue

In this era dangers raided the language of eloquence and statement and the Quran remains the greatest preserved of the sound language, and the greatest certain for its people to preserve its .richness and eloquence, they survive what remained the night and day 
The memorization of the Quran of the best works, and the most important tasks, and the status .of a great keeper, has come several texts showing his status, and what is promised of wages

It is not enough to take science understanding only without conservation, and is not a skillful .man in the Quran quality recitation without conservation, but must be well-preserved

Salaf started to memorize the Koran at a young age, and are keen to start it in the education of their children and do not offer anything of science

To memorize the Holy Quran a great impact in learning Arabic and safety and the development .of skills of the Hafiz and mastery

The teaching of youngness is more established and is the origin of the after; because the former first of hearts Kalasas the basis of the queens and according to the basis and methods will be .based on what, as decided by Ibn Khaldun

The impact of memorizing the Holy Quran in the child's language appears in many aspects, including: the quality of understanding and perception, the integrity of pronunciation and eloquence of the tongue, the integrity of the expression, verbal richness and eloquence of .expression, and mastery of reading and writing

To nurture the child's language by memorizing the Holy Quran practical steps, the most important of which: the graduation in education, repetition and revision, and understand the verses and indicate what is strange

This is God Almighty and success, God bless our Prophet Muhammad and his family and .companions and peace 
(1) رواه ابن ماجه 78/1 برقم (215) و أحمد 127/3 برقم (12301) و النسائي في السنن الكبرى 17/5 برقم (8031) فال شعيب

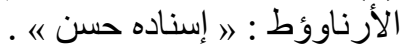

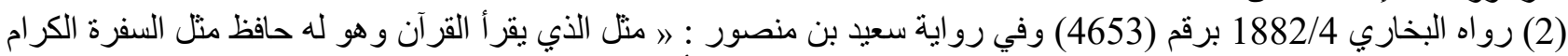

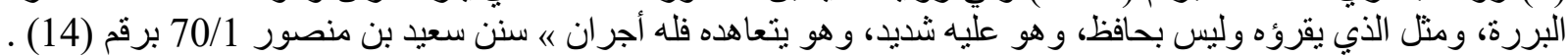
(3) رواه الحاكم في المستدرك

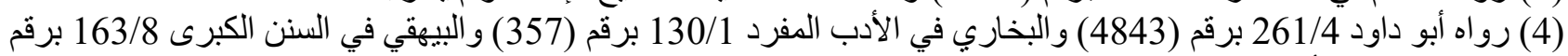
. (16435) وحسنه الألباني أبو داود

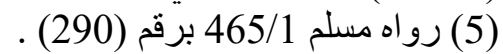

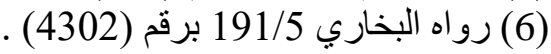
(7) رواه البخاري 178/1 برقم (692/5) برفم (692) .

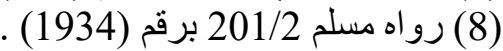

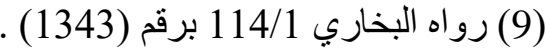

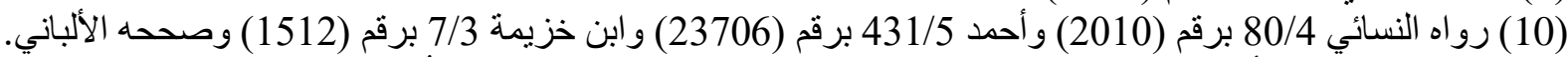

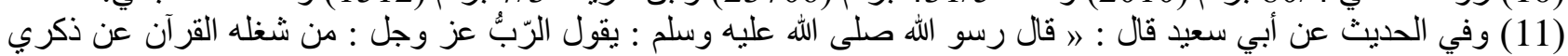

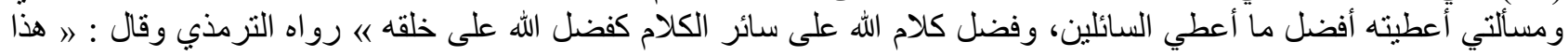

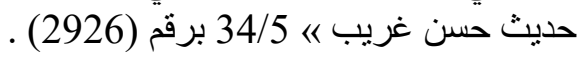

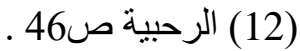

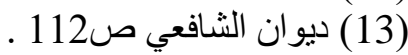

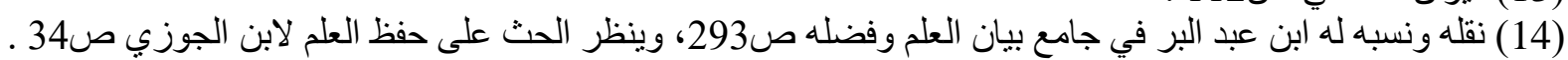

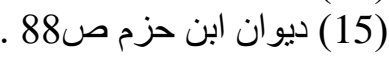

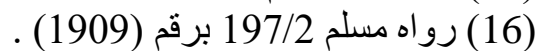
(17) رواه أبو داود 73/2 برقم (1464) ورة (1464) والترمذي 27/5 برقم (2914) وقال » هذا حديث حسن صحيح « وكذلك قال الثيخ

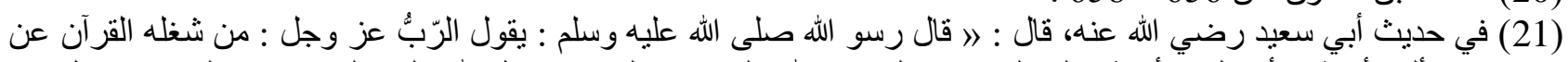

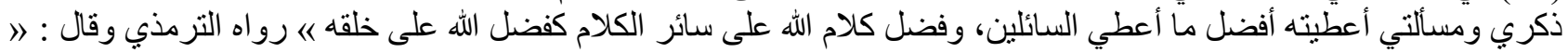

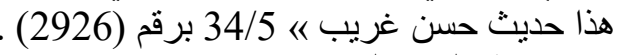

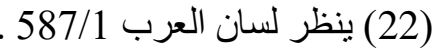
(23) ينظر المز هر في علوم اللغة النة 175/1 ـ

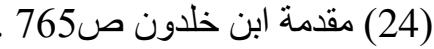

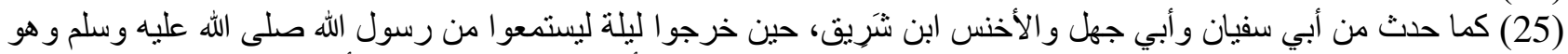

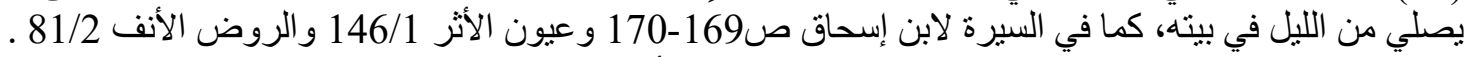

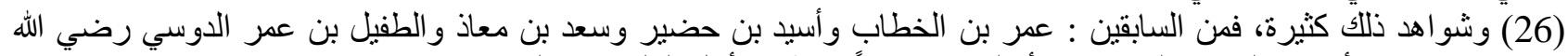

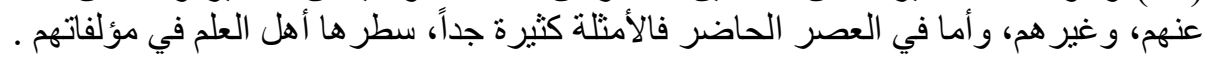

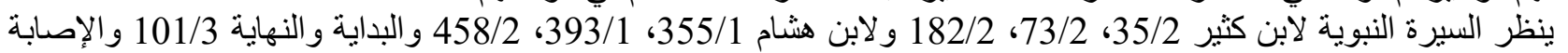

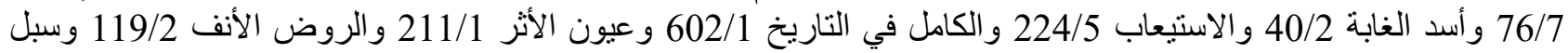

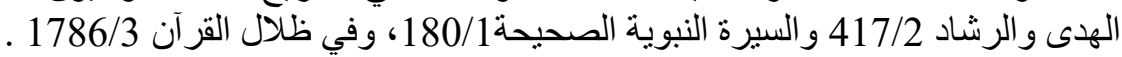

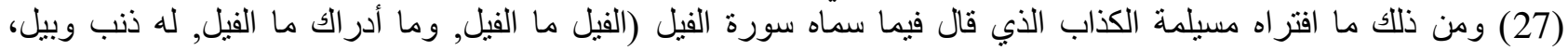

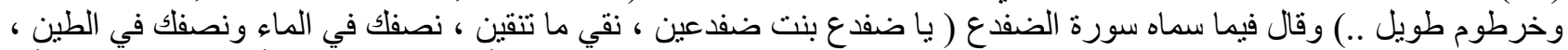

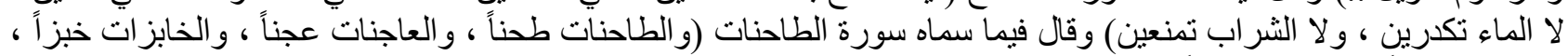

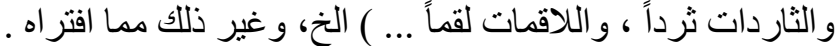

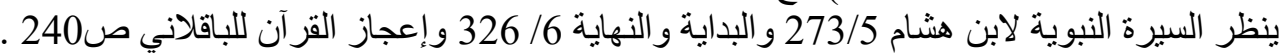

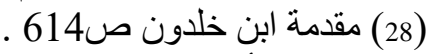
(29) ينظر : أثر حفظ القرآن في تنمية مهار ات الاستقبال اللغوي لدى تلميذات الصف السادس الابتدائي بمكة المكرمة، إعداد أ .

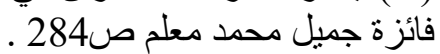
(30) ينظر المصدر السابق، ص281 و أثر حفظ القر آن الكريم في تتمية المهارات اللغوية ص16 ـ 


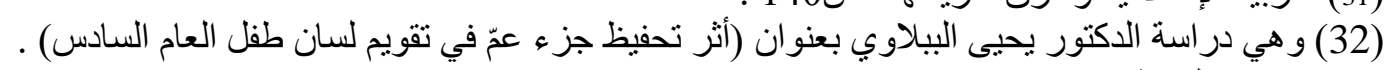

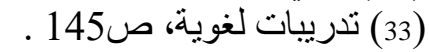

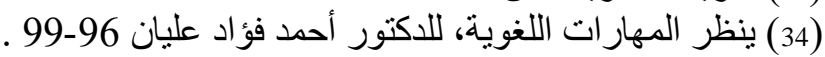

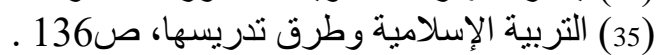

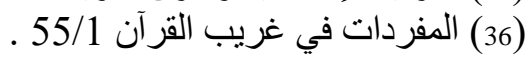

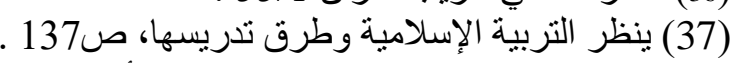

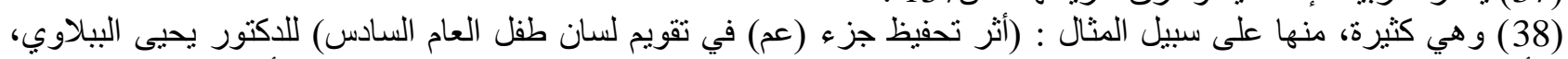

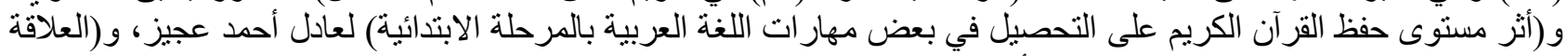

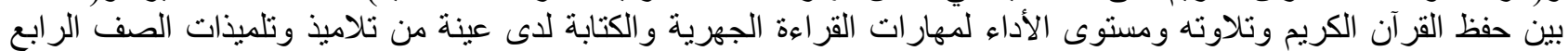

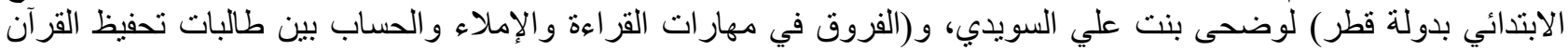

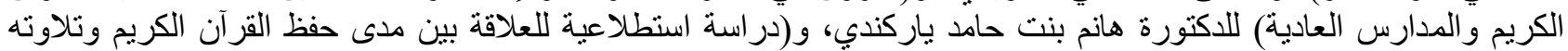

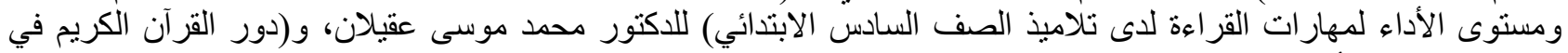

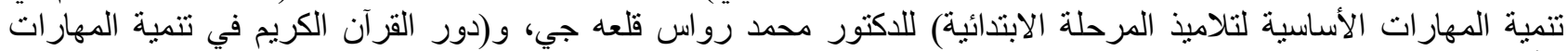

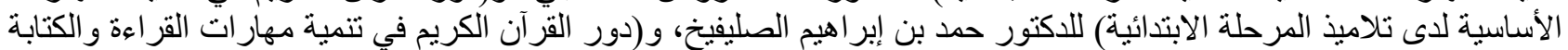

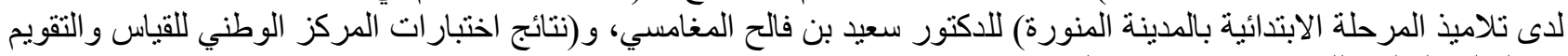

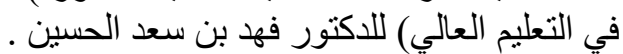

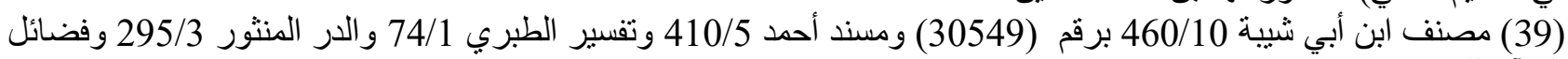

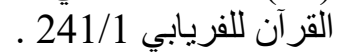

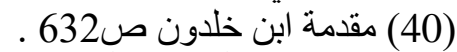
(41) اللغة تدريساً و اكتساباً صنان

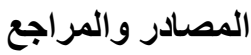

ابن أبي شيبة، عبد الله بن محمد، (بدون تاريخ)، مصنف (بن أبي شبيةة، تحقيق: محمد عوامة، الدار السلفية الهندية ودار القبلة.

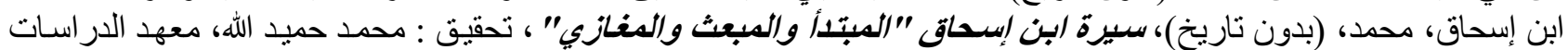
والأبحاث للتعريف، معن.

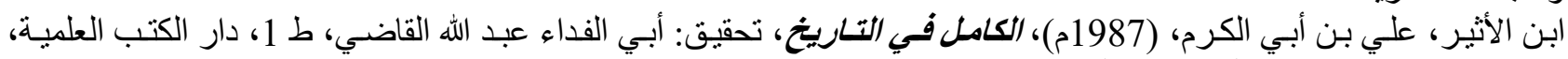

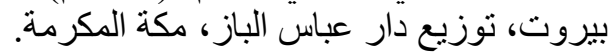

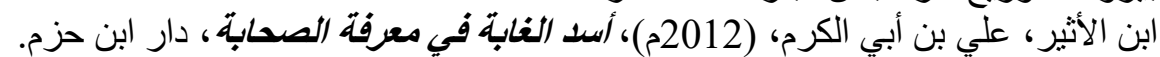

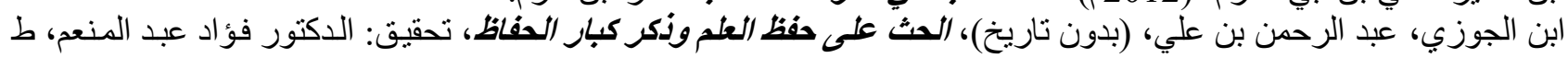
2، مؤسسة شباب الجامعة، بالإسكندرية.

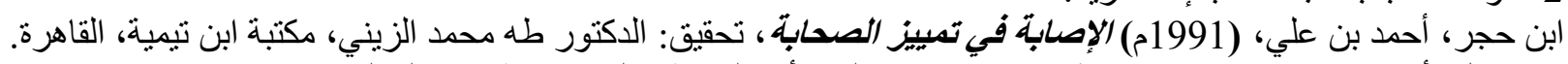

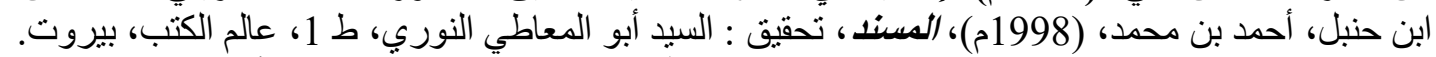

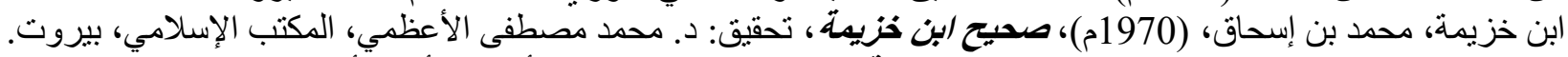

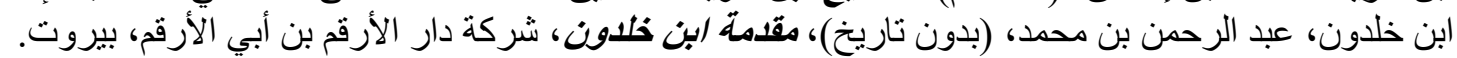

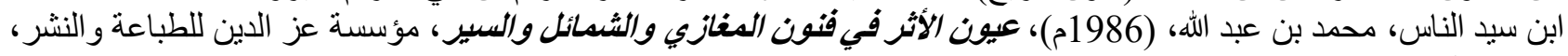
بيروت، لبنان. ابن عبد البر، يوسف بن بن عبد الله، (1991م) الاستيعاب في معرفة الأصحاب، بذيل كتاب الإصـابة في تمييز الصحابة، تحقيق

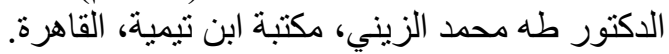

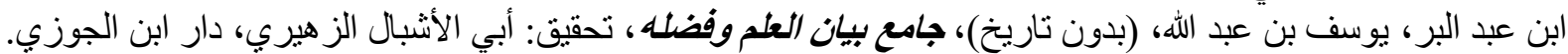

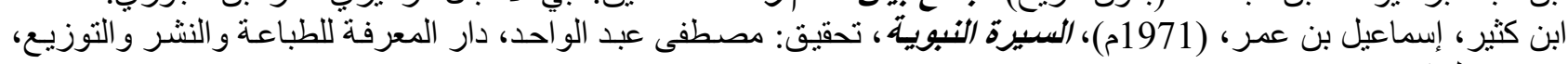
بيروت، لبنان.

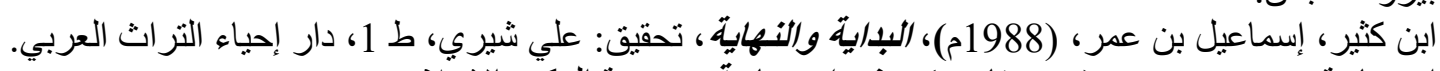

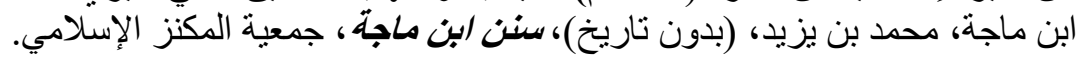

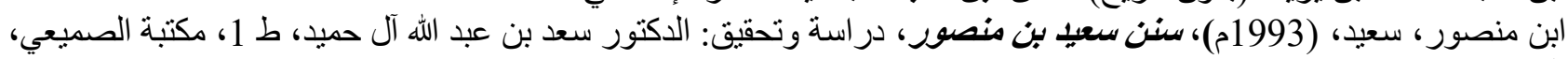

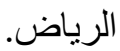

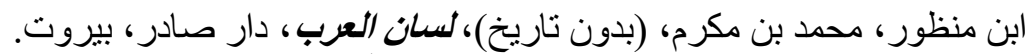

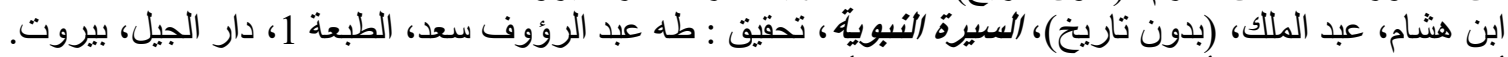

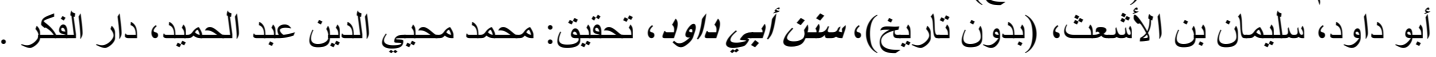


الأصفهاني، الحسين بن محمد الر اغب، (بدون تاريخ)، المفردات في غريب القرآن، تحقيق: صفوان عدنان داودي، دار العلم الدار

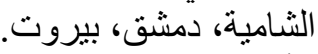

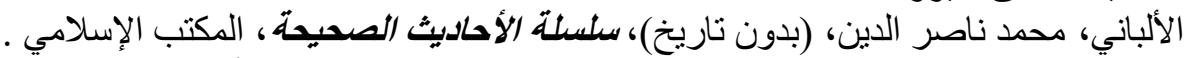

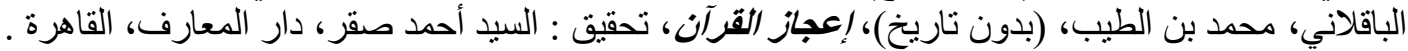

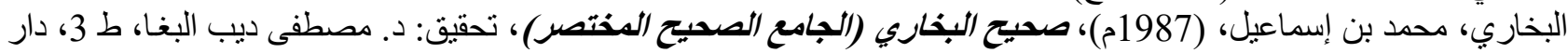

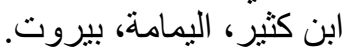

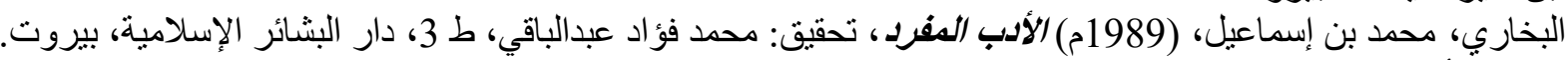

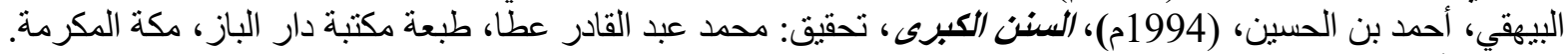

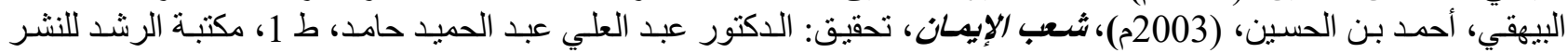
و التوزيع، الرياض، بالتعاون مع الدين، الدار السلفية، بومباي، الإينان، الهند.

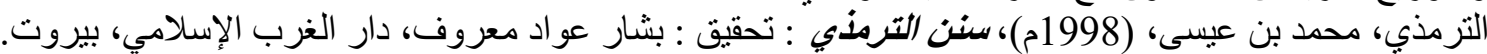

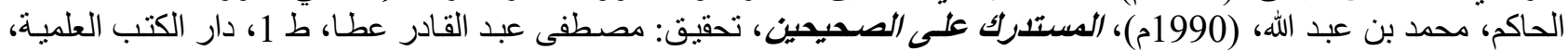
بيروت. الرحبي، محمد بن علي، (1998م)، الرحبية في علم الفرائض مع شرحها لسبط الماربيني، تعليق وتخريج: الدكتور مصطفى ديب

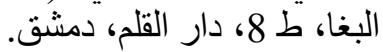
السعيلي، عبد الرحمن بن عبد الله، (بدون تاريخ)، الـروض الأنف في تفسبير السبيرة النبوية ، قدم لـه طه عبدالرؤوف سعد، دار

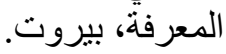

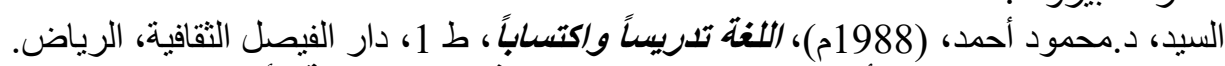

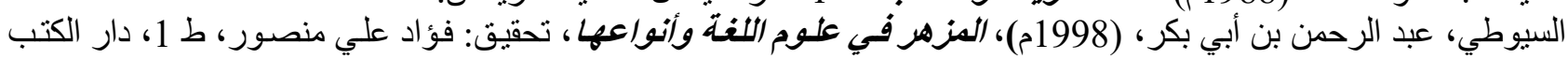

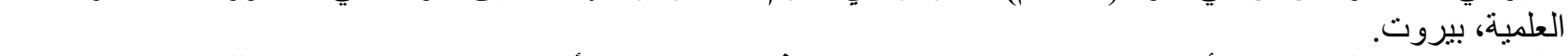
السيوطي، عبد الرحمن بن أبي بكر ، (2003م)، اللدر المنثور في التفسير بالمسأثور، تحقيق: مركز هجر للبحوث، دار هجر،

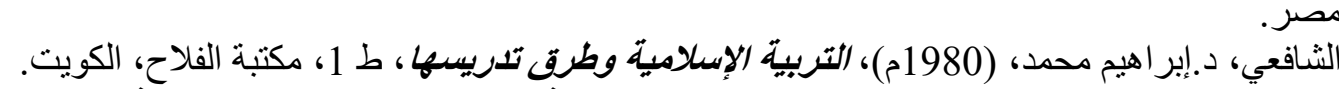

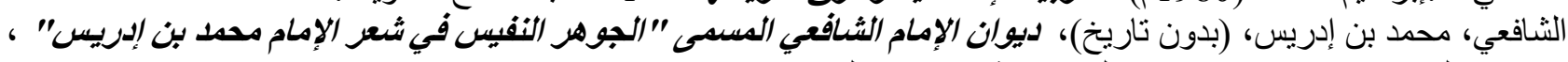

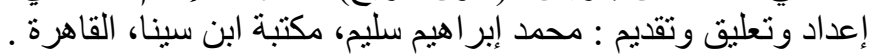

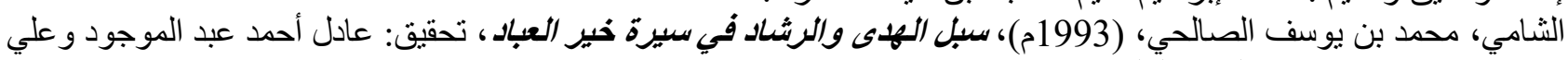

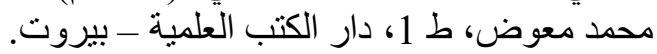
الطبري، محمد بن جرير، (2001م)، جامع البيان عن تأويل آي القرآن، تحقيق: الدكتور عبد الله بن عبد المحسن التركي، دار الظاهري، علي بن أحمد بن حزم، (بدون تاريخ)، ديوان الإمام ابن حزم الظعاهي، جمع وتحقيق ودر اسـة: د. صبحي رشـاد عبد

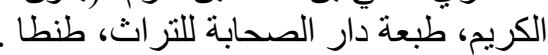

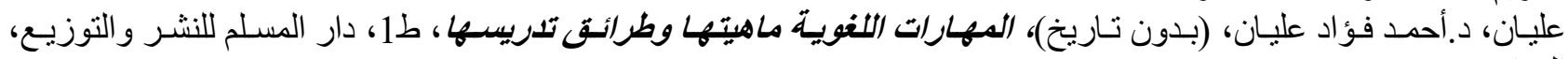

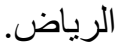

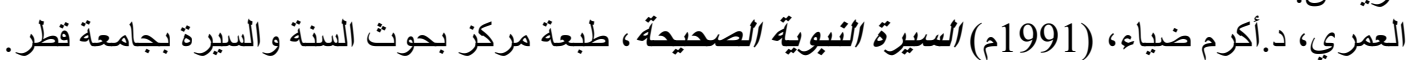

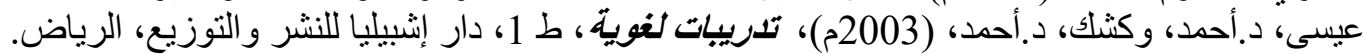

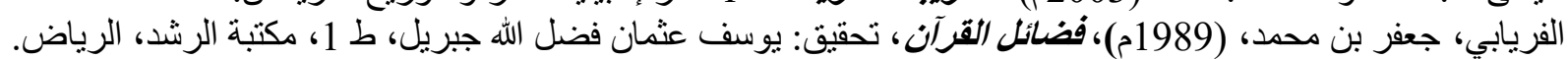

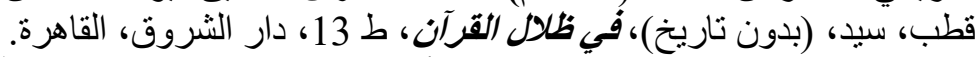

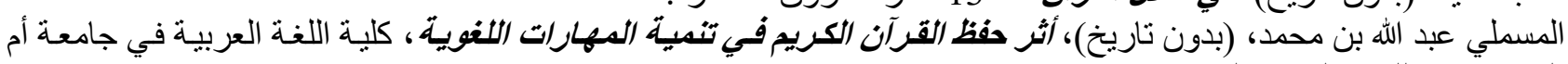

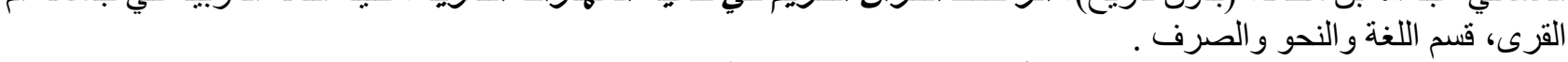
معلم، فائزة بنت جميل محمد، (بدون تاريخ)، أثر حفظ القرآن في تثمية مهارات الاستقبال اللغوي للدى تلكميذات الصف السكاسل

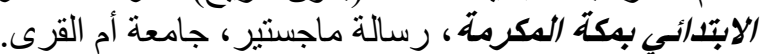

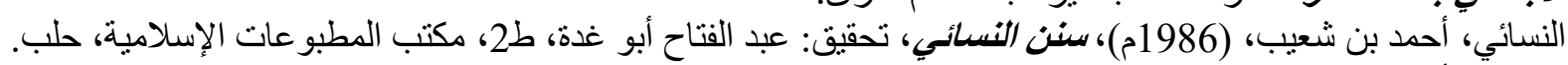
النسائي، أحمد بن شعيب، (1991م)، السنن الكبرى، تحقيق: د.عبد الغفار سليمان البنداري، وسيد كسروي حسن، ط1، دار الكتب الكبان العلمية، بيروت. النبسابوري، مسلم بن الحجاج، (بدون تاريخ)، صحيح مسلم (الجامع الصحيح)، دار الجيل، بيروت، ولئ، ودار الأفاق الجديدة، بيروت.

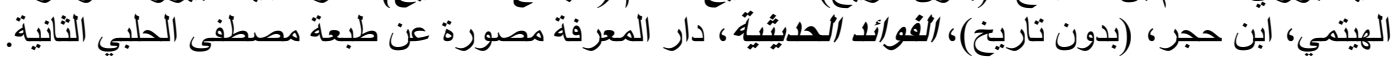




\section{References}

Ibn Abi Shaybah, Abdullah bin Mohammed, (n.d), Classified Ibn Abi Shaybah, investigation: Muhammad Awama, the Salafi House of India and Dar Qibla.

Ibn Ishaq, Muhammad, (n.d), The biography of Ibn Ishaq, "The Beginner, the Emitter, and the Maghazi", by Mohammed Hameedallah, Institute for Studies and Research.

Ibn al-Atheer, Ali ibn Abi al-Karam, (1987), Complete in history, achieve: Abu al-Fida Abdullah al-Qadi, i 1, the House of Scientific Books, Beirut, the distribution of Dar Abbas al-Baz, Mecca.

Ibn al-Atheer, Ali ibn Abi al-Karam, (2012), The lion of the forest in the knowledge of the companions, Dar Ibn Hazm.

Ibn al-Jawzi, Abdul Rahman bin Ali, (n.d), Urging the preservation of science and mention of senior conservation, investigation: Dr. Fouad Abdel Moneim, 2nd floor, University Youth Foundation, Alexandria.

Ibn Hajar, Ahmad Bin Ali, (1991) Injury in the discrimination of the companions, investigation: Dr. Taha Mohammed Zaini, Ibn Taymiyyah Library, Cairo.

Ibn Hanbal, Ahmed bin Mohammed, (1998), Musnad, investigation: Mr. Abu al-Maati al-Nouri, i 1, the world of books, Beirut.

Ibn Khuzaymah, Muhammad ibn Ishaq, (1970), Sahih Ibn Khuzaymah, realization: d. Mohammed Mustafa Al-Adhami, Islamic Bureau, Beirut.

Ibn Khaldun, Abd al-Rahman ibn Muhammad, (n.d), Introduction by Ibn Khaldun, Dar Al Arqam Bin Abi Al Arqam, Beirut.

Ibn Sayyed Al-Nas, Mohammed Bin Abdullah, (1986), Eyes of Archeology in the Art of Maghazi, Al-Shamail and Seer, Ezzedine Foundation for Printing and Publishing, Beirut, Lebanon.

Ibn Abdul Barr, Yusuf bin Abdullah, (1991) Assimilation in the knowledge of the companions, the tail of the book Injury in distinguishing the companions, the investigation of Dr. Taha Mohammed Zaini, Ibn Taymiyyah Library, Cairo.

Ibn Abdul Barr, Yusuf bin Abdullah, (n.d), Collector Bayan science and bounty, achieve: Abu Cubs Zuhairi, Dar Ibn al-Jawzi.

Ibn Katheer, Ismail Bin Omar, (1971), Biography of the Prophet, investigation: Mustafa Abdel Wahed, Dar Al Marefah for printing, publishing and distribution, Beirut, Lebanon.

Ibn Katheer, Ismail bin Omar, (1988), The beginning and the end, the realization: Ali Sherry, i 1, Dar revival of Arab heritage.

Ibn Majah, Muhammad ibn Yazid, (n.d), Sunan Ibn Majah, Thesaurus Islamic Society.

Ibn Mansour, Said, (1993), Sunan Saeed bin Mansour, study and investigation: Dr. Saad bin Abdullah Al-Humaid, i 1, Al-Sumaiy Library, Riyadh.

Ibn Manzoor, Muhammad ibn Makram, (n.d), Lisan Al- Arab, Dar Sader, Beirut. 
Ibn Hisham, Abd al-Malik, (n.d), Biography of the Prophet, Achieved by: Taha Abdel Raouf Saad, 1st edition, Dar Al-Jeel, Beirut.

Abu Dawood, Suleiman ibn al-Ash'ath, (n.d), Sunan Abu Dawood, investigation: Mohammed Mohiuddin Abdul Hamid, Dar thought.

Isfahani, Hussein bin Mohammed Ragheb, (n.d), Vocabulary in the strange Quran, achieve: Safwan Adnan Daoudi, Dar al-Alam Dar al-Shamiya, Damascus, Beirut.

Al-Albani, Muhammad Nasiruddin, (n.d), The series of authentic hadiths, Islamic Office.

Baqlani, Mohammed bin Tayeb, (n.d), The miracle of the Qoran, the investigation: Mr. Ahmed Saqr, Dar al-Maaref, Cairo.

Al-Bukhari, Muhammad ibn Isma'il, (1987), Saheeh al-Bukhari (the right mosque, short), investigation: d. Mustafa Deeb al-Bagha, 3rd floor, Dar Ibn Katheer, Yamama, Beirut.

Al-Bukhari, Muhammad ibn Isma'il, (1989) Singular Literature, Achievement: Mohammed Fouad Abdul Baqi, 3rd floor, Dar Al-Bashaer Al-Islamiyyah, Beirut.

Al-Bayhaqi, Ahmad ibn al-Husayn, (1994), The great Sunnah, realization: Mohammed Abdul Qader Atta, Dar al-Baz library edition, Mecca.

Al-Bayhaqi, Ahmad Bin Al-Hussein, (2003), People of Faith, Investigation: Dr. Abdul Ali Abdul Hamid Hamid, 1st Floor, Al-Rushd Publishing and Distribution Library, Riyadh, in cooperation with Salafi House, Bombay, India.

Tirmidhi, Muhammad ibn Issa, (1998), Sunan Tirmidhi: Investigation: Bashar Awad Marouf, Islamic House of the West, Beirut.

The ruler, Mohammed bin Abdullah, (1990), But the right, the investigation: Mustafa Abdel Qader Atta, I 1, House of scientific books, Beirut.

Rahbi, Mohammed bin Ali, (1998), Rahbia in the science of statutes with an explanation of the tribe of Mardini, commentary and graduation: Dr. Mustafa Deeb Al-Bagha, i 8, Dar AlQalam, Damascus.

Suhaili, Abdul Rahman bin Abdullah, (n.d), Rawd nose in the interpretation of the biography of the Prophet, presented to him Taha Abdul Raouf Saad, House of Knowledge, Beirut.

Mahmoud Ahmed, (1988), Language teaching and acquisition, I 1, Dar Al-Faisal Cultural, Riyadh.

Al-Suyooti, Abdul Rahman bin Abi Bakr, (1998), Al-Mizhar in Language Sciences and Types, Achieved by: Fouad Ali Mansour, 1st Floor, Scientific Books House, Beirut.

Al-Suyooti, Abdul Rahman bin Abi Bakr, (2003), Al-Dur Al-Manthoor in Interpretation of AlMa'thour, An Inquiry: Hajar Research Center, Dar Hajar, Egypt.

Shafei, Dr. Ibrahim Mohammed, (1980), Islamic education and methods of teaching, I 1, Al-Falah Library, Kuwait.

Shafei, Mohammed bin Idris, (n.d), The Imam Shafei Court called "the essence of precious poetry of Imam Muhammad bin Idris", prepared, commented and presented: Mohammed Ibrahim Selim, Ibn Sina Library, Cairo. 
Al-Shami, Mohammed bin Yousef Al-Salhi, (1993), Ways of guidance and guidance in the biography of Khair al-Abad, investigation: Adel Ahmed Abdel Mawgoud and Ali Mohammed Moawad, 1st floor, Scientific Books House - Beirut.

Tabari, Mohammed bin Jarir, (2001), Collector statement on the interpretation of any Quran, investigation: Dr. Abdullah bin Abdul Mohsen Turki, Dar Hajar.

Al-Dhaheri, Ali bin Ahmed bin Hazm, (n.d), The Office of Imam Ibn Hazm al-Dhaheri, collection, investigation and study: d. Sobhi Rashad Abdel Karim, edition of the companions House of Heritage, Tanta.

Olayan, d. Ahmed Fouad Olayan, (n.d), The language skills and methods of teaching, I 1, House of the Muslim Publishing and Distribution, Riyadh.

Al-Omari, d. Akram Zia, (1991) The correct prophetic biography, edition of the Center for Research of Sunnah and Biography at Qatar University.

Issa, d. Ahmed, and kiosk, d. Ahmed, (2003), Language training, i 1, Dar Ishbilia for publication and distribution, Riyadh.

Al-Faryabi, Ja'far Bin Mohammed, (1989), The Virtues of the Qur'an, Achievement: Yousef Othman Fadlallah Jibril, 1st Floor, Al-Rushd Library, Riyadh.

Qutb, Sayed, (n.d), In the shadows of the Quran, i 13, Dar el-Shorouk, Cairo

Al-Masmali, Abdullah bin Mohammed, (n.d), The effect of memorizing the Holy Quran on the development of language skills, Faculty of Arabic Language at the University of Umm AlQura, Department of Language, grammar and morphology.

Moallem, Faiza bint Jameel Mohammed, (n.d), The effect of memorizing the Qur'an on the development of language reception skills for sixth grade students in Makkah, Master Thesis, Umm Al-Qura University.

Al-Nasaa'i, Ahmad Bin Shuaib, (1986), Sunan Al-Nasaa'i, Investigation: Abdul Fattah Abu Ghadda, 2nd Floor, Islamic Publications Office, Aleppo.

Al-Nasaa'i, Ahmad Bin Shuaib, (1991), The Great Sunnah, Investigation: Dr. Abdul Ghaffar Suleiman Al-Bandari, Sayyid Kisrawi Hassan, 1st Floor, Scientific Books House, Beirut.

Nisaburi, Muslim ibn al-Hajjaj, (n.d), Sahih Muslim (right mosque), Dar al-Jeel, Beirut, and House of New Horizons, Beirut.

Al-Hitmi, Ibn Hajar, (n.d), The modern benefits, Dar Al-Marefa illustrated on the second edition of Mustafa Al-Halabi. 